Jurnal Penelitian Hutan Tanaman Vol. 16 No. 2, Desember 2019, 59-72

ISSN: 1829-6327, E-ISSN: 2442-8930

Terakreditasi No: 21/E/KPT/2018

\title{
PEMATAHAN DORMANSI DAN METODE UJI VIABILITAS BENIH LAMTORO \\ (Leucaena leucocephala Lam. de Wit.) \\ (Breaking Dormancy and Testing Method in Determining Seed Viability of Lamtoro
}

(Leucaena leucocephala Lam. De Wit.)

\author{
Eliya Suita \\ Balai Penelitian Pengembangan Teknologi Perbenihan Tanaman Hutan Bogor \\ Jl. Pakuan, Ciheuleut PO Box 105, Jawa Barat, Bogor 16121. \\ Email: eliyasuita@yahoo.co.id
}

Tanggal diterima: 14 Maret 2019; Tanggal disetujui: 1 Juni 2019; Tanggal direvisi: 8 Oktober 2019

\begin{abstract}
Due to its hard seed coat condition, preliminary treatment is necessary to be applied to Lamtoro seed to improve its germination. The objective of this research was to figure out the best pre-treatment and testing method for improving seed viability and seed vigor of lamtoro. Completely randomized design with factorial patterns was arranged to assist analyzing the observed parameters. Pre-treatments for breaking seed dormancy was conducted including: control (without treatment), soaked seeds in plain water for 24 hours, soaked seeds in boiling water $\left(100^{\circ} \mathrm{C}\right)$ and colded for 24 hours, soaked seeds in concentrated $\mathrm{H}_{2} \mathrm{SO}_{4}$ for 10 and 20 minutes, soaked seeds in $1 \% \mathrm{NaOCl}$ for 5 and 10 minutes. The test results showed the best viability of lamtoro seed through sowing in both a greenhouse and laboratory that can increase germination, germination speed, germination rate and germination value was the treatment of soaked seeds in $\mathrm{H}_{2} \mathrm{SO}_{4}$ for 20 minutes. The best sowing test method in a greenhouse is obtained from a mixture of sand and soil media $(1: 1, v / v)$ covered with sand and in a laboratory with Top of Paper method.
\end{abstract}

Keywords: Lamtoro, pre-treatments, testing method, and viability

\begin{abstract}
ABSTRAK
Benih lamtoro mempunyai kulit yang keras sehingga untuk meningkatkan dan mempercepat perkecambahan diperlukan perlakuan pendahuluan agar mempunyai viabilitas dan vigor yang tinggi. Tujuan penelitian ini adalah mendapatkan perlakuan pendahuluan dan metode uji yang sesuai agar dihasilkan tingkat perkecambahan yang tinggi. Penelitian menggunakan rancangan acak lengkap pola faktorial dengan perlakuan: control (tanpa perlakuan), benih direndam air biasa selama 24 jam, benih direndam air panas (suhu $100^{\circ} \mathrm{C}$ ) dan dibiarkan dingin selama $24 \mathrm{jam}$, benih direndam dalam $\mathrm{H}_{2} \mathrm{SO}_{4}$ pekat selama 10 dan 20 menit, serta benih direndam dalam $\mathrm{NaOCl} 1 \%$ selama 5 dan 10 menit. Hasil pengujian menunjukkan pengujian viabilitas benih lamtoro yang terbaik melalui penaburan di rumah kaca maupun di laboratorium yang dapat meningkatkan daya berkecambah, kecepatan berkecambah, laju perkecambahan dan nilai perkecambahan apabila diberikan perlakuan benih direndam dengan $\mathrm{H}_{2} \mathrm{SO}_{4}$ selama 20 menit. Metode uji penaburan terbaik di rumah kaca diperoleh dari media campuran pasir dan tanah $(1: 1, \mathrm{v} / \mathrm{v})$ ditutup pasir dan di laboratorium dengan metode uji di atas kertas.
\end{abstract}

Kata kunci: Lamtoro, perlakuan pendahuluan, metode uji, viabilitas 


\section{PENDAHULUAN}

Lamtoro (Leucaena leucocephala (Lam.) de Wit.), terkenal sebagai tanaman multiguna dan dapat tumbuh di dataran rendah dan dataran tinggi, hingga ketinggian $1.500 \mathrm{~m}$ dpl. Curah hujan tahunan yang diperlukan berkisar 650-3.000 mm. Lamtoro terutama disukai sebagai penghasil kayu api atau kayu energi. Kayu lamtoro memiliki nilai kalor yang tinggi $4.600 \mathrm{kal} / \mathrm{kg}$. (Orwa, Mutua, Kindt, \& Anthony, 2009). Daun lamtoro sangat bergizi untuk makanan ternak. Tanaman lamtoro juga dapat digunakan dalam sistem tanam, yang berfungsi sebagai pengontrol erosi pada lereng curam dan sebagai bentuk tanaman lorong. Tanaman lamtoro bermanfaat sebagai penahan angin dan pemecah api. Daun lamtoro dapat juga digunakan sebagai pupuk yaitu, dengan pupuk cair daun lamtoro dapat memberikan pengaruh terhadap pertumbuhan dan perkembangan tanaman sawi pakcoy dengan konsentrasi $100 \mathrm{ml}$ (Roidi, 2016).

Untuk mendukung berhasilnya penanaman, maka dibutuhkan bibit dalam jumlah yang cukup dan tepat waktu. Namun ada kendala penyemaian benih lamtoro, yaitu benih lamtoro mempunyai kulit yang keras (dormansi fisik). Untuk mengatasi permasalahan tersebut, maka perlu penanganan benih melalui perlakuan pendahuluan guna meningkatkan dan mempercepat perkecambahan. Menurut (Murniati, 2013). Dormansi adalah suatu kodisi dimana benih hidup tidak berkecambah sampai batas waktu akhir pengamatan perkecambahan walaupun faktor lingkungan optimum untuk perkecambahannya. Benih-benih yang mempunyai kulit benih yang keras, dapat ditingkatkan daya berkecambahnya dengan bermacam-macam perlakuan pendahuluan tergantung sifat fisik benih itu sendiri. Hasil-hasil penelitian perlakuan pendahuluan yang telah dilakukan untuk jenis-jenis yang sulit berkecambah, untuk jenis lamtoro (Tadros, Samarah, \& Alqudah, 2011) menyatakan bahwa benih lamtoro direndam dalam air $70^{\circ} \mathrm{C}$ selama 20 menit efektif untuk memecahkan dormansi benih dan dapat menghasilkan daya berkecambah $68 \%$, sedangkan (Fitri, 2015) menyatakan bahwa skarifikasi dengan perendaman dalam air panas selama 6 menit menghasilkan daya berkecambah $58 \%$ dan dalam asam sulfat selama 20 menit menghasilkan daya berkecambah $50 \%$. Untuk jenis-jenis yang sulit berkecambah lainnya (Olatunji, Maku, \& Odumefun, 2013) untuk jenis Acacia auriculiformis A. Cunn. ex Benth, perlakuan perendaman dengan $\mathrm{H}_{2} \mathrm{SO}_{4}$ selama 5-10 menit memiliki persentase perkecambahan tertinggi (92-96\%), begitu juga dengan hasil penelitian (Rasebeka, Mathowa, \& Mojeremane, 2014) untuk jenis A. tortilis, A. erioloba, dan A. nigrescens yang menyarankan menggunakan asam sulfat pekat dan air panas untuk perlakuan pendahuluan tiga jenis Acacia untuk meningkatkan perkecambahannya, sedangkan untuk jenis sengon (Marthen, Kaya, \& Rehatta, 2013), benih yang dicelupkan ke dalam air panas $60^{\circ} \mathrm{C}$ selama 4 menit, dilanjutkan dengan perendaman air dingin selama 12 jam dapat menghasilkan persentase perkecambahan mencapai $100 \%$.

Dari hasil-hasil penelitian yang sudah ada, untuk mendapatkan viabilitas benih lamtoro yang optimal, maka perlu dilakukan pengujian perkecambahan dengan memberikan berbagai macam perlakuan pendahuluan dengan menggunakan beberapa metode uji, baik di rumah kaca maupun di laboratorium, agar mendapatkan perkecambahan yang dapat menghasilkan viabilitas dan vigor yang tinggi. Tujuan penelitian ini adalah untuk mendapatkan perlakuan pendahuluan dan metode uji yang sesuai agar dihasilkan tingkat perkecambahan yang tinggi. 


\section{METODOLOGI}

\section{A. Tempat dan Waktu Penelitian}

Benih lamtoro diunduh di Jorong Balai Batu Aceh, Desa Cupak, Kecamatan Gunung Talang, Kabupaten Solok, Sumatera Barat pada tahun 2013. Penelitian dilaksanakan di laboratorium dan rumah kaca Balai Penelitian dan Pengembangan Teknologi Perbenihan Tanaman Hutan, Bogor.

\section{B. Prosedur Penelitian}

Buah/polong yang dikumpulkan adalah buah/polong yang sudah masak fisiologis yang ditandai dengan buah/polong sudah berwarna kecoklatan dan sudah mulai merekah. Ekstraksi dilakukan dengan cara, buah/polong dijemur di bawah sinar matahari 2-3 hari atau sampai buah/polong merekah, kemudian benih dipisahkan dari kulitnya. Benih hasil ekstraksi diuji perkecambahannya.

\section{Metode Uji Perkecambahan}

Pengujian perkecambahan meliputi pengujian di laboratorium dan pengujian di rumah kaca. Pengujian di laboratorium menggunakan rancangan faktorial dalam rancangan acak lengkap. Faktor petama berupa perlakuan pendahuluan yang terdiri atas 7 taraf dan faktor kedua berupa metode uji perkecambahan yang terdiri atas 3 taraf. Setiap kombinasi perlakuan diulang 4 kali dengan masing-masing unit percobaan terdiri dari 50 butir benih lamtoro. Faktor perlakuan pendahuluan (A) yaitu:

A1 : Kontrol (tanpa perlakuan)

A2 : Benih direndam dengan air biasa selama 24 jam

A3 : Benih direndam dalam air panas (suhu $100^{\circ}$ C) dan dibiarkan dingin selama 24 jam

A4 : Benih direndam dalam $\mathrm{H}_{2} \mathrm{SO}_{4}$ pekat selama 10 menit

A5 : Benih direndam dalam $\mathrm{H}_{2} \mathrm{SO}_{4}$ pekat selama 20 menit

A6 : Benih direndam dalam $\mathrm{NaOCl} 1 \%$ selama 5 menit

A7 : Benih direndam dalam $\mathrm{NaOCl} 1 \%$ selama 10 menit

Faktor metoda uji perkecambahan dilakukan di laboratorium:

B1 : UDK (Uji Di Atas Kertas)

B2 : UAK (Uji Antar Kertas)

B3 : UKDdp (Uji Kertas Digulung didirikan dalam plastik)

Pengujian di rumah kaca menggunakan Rancangan Faktorial dalam Rancangan Acak Lengkap dengan faktor pertama berupa perlakuan pendahuluan yang terdiri atas 7 taraf dan faktor kedua berupa media perkecambahan yang terdiri atas 2 taraf. Setiap kombinasi perlakuan diulang 4 kali dengan masing-masing unit percobaan terdiri dari 50 butir benih lamtoro. Faktor perlakuan pendahuluan (A) yaitu:

A1 : Kontrol (Control)

A2 : Benih direndam dengan air biasa selama 24 jam (Soaked seeds in blain plain water for 24 hours)

A3 : Benih direndam dalam air panas (suhu $100^{\circ} \mathrm{C}$ ) dan dibiarkan dingin selama 24 jam (Soaked seeds in boiling water $\left(100^{\circ} \mathrm{C}\right)$ and colded for 24 hours)

A4 : Benih direndam dalam $\mathrm{H}_{2} \mathrm{SO}_{4}$ pekat selama 10 menit (Soaked seeds in concentrated $\mathrm{H}_{2} \mathrm{SO}_{4}$ for 10 minutes)

A5 : Benih direndam dalam $\mathrm{H}_{2} \mathrm{SO}_{4}$ pekat selama 20 menit (Soaked seeds in concentrated $\mathrm{H}_{2} \mathrm{SO}_{4}$ for 20 minutes)

A6 : Benih direndam dalam $\mathrm{NaOCl} 1 \%$ selama 5 menit (Soaked seeds in $1 \% \mathrm{NaOCl}$ for 5 minutes)

A7 : Benih direndam dalam $\mathrm{NaOCl} 1 \%$ selama 10 menit (Soaked seeds in $1 \% \mathrm{NaOCl}$ for 10 minutes)

Faktor media perkecambahan di rumah kaca meliputi:

C1 : Media pasir tanah (1:1) terbuka (Uncovered sand-soil media (1:1))

C2 : Media pasir tanah (1:1) ditutup plastik selama 1 minggu pertama 
(Sand-soil media (1:1) covered with plastic for the $1^{\text {st }}$ week)

Respon yang diamati adalah daya berkecambah, kecepatan berkecambah, laju perkecambahan dan nilai kecambah. Perkecambahan benih (daya berkecambah dan kecepatan berkecambah), ditentukan dengan jumlah benih yang sudah berkecambah normal. Daya berkecambah menjabarkan tolok ukur viabilitas potensial dan rumus daya berkecambah (DB) adalah :

Daya Berkecambah (DB) $=\frac{\Sigma \mathrm{KN}}{\mathrm{N}} \mathrm{x} 100 \%$

DB = Daya berkecambah

$\sum \mathrm{KN}=$ Jumlah kecambah normal yang dihasilkan

$\mathrm{N}=$ Jumlah contoh benih yang diuji

Kecepatan berkecambah yang dihitung adalah benih yang berkecambah dari hari pengamatan ke-1 sampai dengan hari terakhir. Dengan penghitungan kecambah normal pada setiap pengamatan dibagi dengan etmal $(1$ etmal $=24$ jam $)$. Menurut (Widajati, 2013), kecepatan berkecambah menjabarkan parameter vigor dan rumus Kecepatan berkecambah sebagai berikut:

$\mathrm{Kct}=\frac{\sum_{\mathrm{i}=1}^{\mathrm{n}} \text { Persen benih berkecambah sejak hari pertama }}{\text { etmal }}$

Dimana:

Kct = Kecepatan berkecambah

$\mathrm{i} \quad=$ Hari pengamatan

etmal $=24 \mathrm{jam}$

Laju perkecambahan dapat diukur dengan menghitung jumlah hari yang diperlukan untuk munculnya radikel atau plumula.

Rata - rata hari $=\frac{\mathrm{N} 1 \mathrm{~T} 1+\mathrm{N} 2 \mathrm{~T} 2+\cdots+\mathrm{NxTx}}{\text { Jumlah total benihyang berkecambah }}$

Dimana:

$\mathrm{N}=$ Jumlah benih yang berkecambah pada satuan waktu tertentu

$\mathrm{T}=$ Jumlah waktu awal pengujian sampai akhir pengamatan

Nilai perkecambahan: mencakup laju dan persentase perkecambahan
Nilai puncak $=\frac{\text { Persen perkecambahan pada walku } T}{\text { Jumlah hari yang diperlukan untuk mencapainya }}$

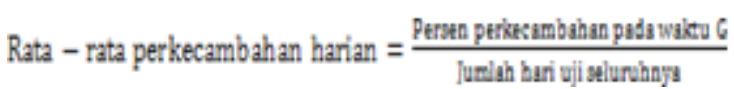

Nilai perkecambahan $=$ nilai puncak $\mathrm{x}$ nilai rata-rata perkecambahan harian

Dimana:

$\mathrm{T}=$ Titik dimana laju perkecambahan mulai menurun

$\mathrm{G}=$ Titik dimana perkecambahan benih berakhir

\section{Analisis Data}

Analisis ragam digunakan untuk menguji pengaruh perlakuan pendahuluan dan metode uji benih lamtoro terhadap perkecambahan benih di rumah kaca dan laboratorium. Uji Duncan (Duncan Multiple Range Test) digunakan untuk membedakan nilai tengah antar perlakuan yang diuji bila hasil analisis ragam dari perlakuan-perlakuan tersebut menunjukkan pengaruh yang nyata.

\section{HASIL DAN PEMBAHASAN}

\section{A. Hasil}

\section{Pengujian di rumah kaca}

Hasil analisis statistika menunjukkan bahwa perlakuan pendahuluan dan metode uji perkecambahan benih lamtoro yang diuji di rumah kaca, berpengaruh secara nyata terhadap daya berkecambah, kecepatan berkecambah, dan laju perkecambahan. Untuk nilai perkecambahan hanya perlakuan pendahuluan yang berbeda, sedangkan untuk metode ujinya tidak berbeda secara nyata. Terhadap daya berkecambah terjadi interaksi yang signifikan antara perlakuan pendahuluan dan metode uji (Tabel 1). Selanjutnya dilakukan uji beda rata-rata dengan menggunakan Uji Duncan.

Hasil Uji Duncan (Tabel 2), interaksi antara perlakuan pendahuluan dan metode uji menunjukkan bahwa daya kecambah tertinggi dihasilkan pada perlakuan benih diberi perlakuan direndam dalam $\mathrm{H}_{2} \mathrm{SO}_{4}$ 
selama 10 menit dan 20 menit ( $\mathrm{A}_{4}$ dan $\left.\mathrm{A}_{5}\right)$ dengan metode uji ditabur pada media pasir : tanah $(1: 1, \mathrm{v} / \mathrm{v})$ dengan bak kecambah terbuka $\left(\mathrm{C}_{1}\right)$ dengan daya kecambah $90,00 \%$ dan $89,33 \%$, dan benih yang ditabur pada media pasir : tanah $(1: 1$, $\mathrm{v} / \mathrm{v})$ yang ditutup plastik $\left(\mathrm{C}_{2}\right)$ dengan perlakuan pendahuluan benih direndam dalam $\mathrm{H}_{2} \mathrm{SO}_{4}$ selama 20 menit $\left(\mathrm{A}_{5}\right)$ yang menghasilkan daya kecambah (88\%). Daya berkecambah terendah terdapat pada benih yang diberi perlakuan direndam $\mathrm{NaOCl} 1 \%$ selama 10 menit baik ditabur di media pasir terbuka maupun tertutup plastik ( $\mathrm{A}_{6}$ dan $\left.\mathrm{A}_{7}\right)$ dengan nilai daya berkecambah $10 \%$ dan $27 \%$. Benih yang direndam air biasa selama 24 jam $\left(\mathrm{A}_{2}\right)$ yang ditabur pada media terbuka $\left(\mathrm{C}_{1}\right)$ maupun tertutup $\left(\mathrm{C}_{2}\right)$ belum dapat meningkatkan daya berkecambah, sedangkan benih yang direndam air panas $\left(\mathrm{A}_{3}\right)$ dapat meningkatkan daya berkecambah benih lamtoro $28 \%$ apabila ditabur di media terbuka $\left(\mathrm{C}_{1}\right)$ dan $10 \%$ di media tertutup $\left(\mathrm{C}_{2}\right)$.

Sesuai dengan hasil uji beda nyata (Tabel 3), perlakuan pendahuluan yang dapat menghasilkan kecepatan perkecambahan tertinggi adalah perlakuan pendahuluan benih direndam $\mathrm{H}_{2} \mathrm{SO}_{4}$ selama 20 menit $\left(\mathrm{A}_{5}\right)$ dengan kecepatan berkecambah $\quad(16,23 \% \quad \mathrm{KN} / \mathrm{etmal})$, sedangkan benih dengan perlakuan direndam $\mathrm{NaClO} 1 \%$ selama 5 menit dan 10 menit $\left(\mathrm{A}_{6}\right.$ dan $\left.\mathrm{A}_{7}\right)$ dan yang direndam air biasa selama 24 jam $\left(\mathrm{A}_{2}\right)$ menghasilkan kecepatan berkecambah yang tidak berbeda nyata dengan kontrol $\left(\mathrm{A}_{1}\right)$.

Laju perkecambahan dapat dipengaruhi oleh perlakuan pendahuluan. Hasil yang tertinggi dihasilkan pada perlakuan pendahuluan benih direndam
$\mathrm{H}_{2} \mathrm{SO}_{4}$ selama 20 menit $\left(\mathrm{A}_{5}\right)$, dengan laju perkecambahan 5,75 hari, tetapi tidak berbeda nyata dengan perlakuan yang direndam $\mathrm{H}_{2} \mathrm{SO}_{4}$ selama 10 menit $\left(\mathrm{A}_{4}\right)$ dan yang direndam air panas $\left(\mathrm{A}_{3}\right)$, dengan laju perkecambahan 6,82 hari dan 7,30 hari. Laju perkecambahan pada benih yang direndam air biasa $\left(\mathrm{A}_{2}\right)$ dan yang direndam $\mathrm{NaClO} \quad\left(\mathrm{A}_{6}\right.$ dan $\left.\mathrm{A}_{7}\right)$ tidak berbeda nyata dengan kontrol $\left(\mathrm{A}_{1}\right)$. Hasil tertinggi didapatkan pada perlakuan benih direndam dengan $\mathrm{H}_{2} \mathrm{SO}_{4}$ selama 20 menit (A) dengan nilai perkecambahan 39,62.

Metode uji dapat mempengaruhi kecepatan berkecambah dan laju perkecambahan (Tabel 4). Benih yang ditabur di media pasir : $\operatorname{tanah}(1: 1, \mathrm{v} / \mathrm{v})$ dengan ditutup plastik $\left(\mathrm{C}_{2}\right)$, menghasilkan kecepatan berkecambah tertinggi yaitu 7,34\%/etmal, begitu juga laju perkecambahan metode uji $\mathrm{C}_{2}$ lebih cepat 2,08 hari daripada metode uji $\mathrm{C}_{1}$.

\section{Hasil perkecambahan di laboratorium}

Hasil analisis statistik menunjukkan bahwa faktor perlakuan pendahuluan benih lamtoro yang diuji di laboratorium berpengaruh secara nyata terhadap daya berkecambah, kecepatan berkecambah, laju perkecambahan dan nilai perkecambahan, sedangkan faktor metode ujinya hanya berpengaruh signifikan terhadap nilai perkecambahan. Interaksi antara perlakuan pendahuluan dan metode uji yang berbeda signifikan terjadi pada parameter daya berkecambah, kecepatan berkecambah dan nilai berkecambah (Tabel 5). Untuk hasil yang berbeda nyata dilanjutkan dengan Uji Duncan 
Tabel (Table) 1. Hasil analisis keragaman daya berkecambah, kecepatan berkecambah, laju perkecambahan dan nilai perkecambahan benih lamtoro terhadap perlakuan pendahuluan dan kondisi penaburan (The analysis results on germination percentage, germination rate, mean daily germination and germination value of the lamtoro seeds on the pre-treatments and sowing conditions in the greenhouse)

\begin{tabular}{|c|c|c|c|c|}
\hline Sumber (Sources) & $\begin{array}{c}\text { Daya berkecambah } \\
\text { (Germination } \\
\text { percentage) } \\
(\%)\end{array}$ & $\begin{array}{c}\text { Kecepatan } \\
\text { perkecambahan } \\
\text { (Germination rate }) \\
(\% / \text { etmal })\end{array}$ & $\begin{array}{c}\text { Laju Perkecam- } \\
\text { bahan (Mean Daily } \\
\text { Germination) } \\
\text { (Hari/Days) }\end{array}$ & $\begin{array}{c}\text { Nilai perkecam- } \\
\text { bahan } \\
\text { (Germination } \\
\text { Value })\end{array}$ \\
\hline $\begin{array}{l}\text { Perlakuan } \\
\text { pendahuluan (Pre- } \\
\text { treatments) (A) }\end{array}$ & $267,13 * *$ & $435,05 * *$ & $31,85^{* *}$ & $180,86^{* *}$ \\
\hline $\begin{array}{l}\text { Metode uji } \\
\text { penaburan (Testing } \\
\text { method) (B) }\end{array}$ & $69,94 * *$ & $32,48^{* *}$ & $9,27 * *$ & $3,63^{\mathrm{tn}}$ \\
\hline $\begin{array}{l}\text { Interaksi } \\
(\text { Interaction }) \\
(\mathrm{A}) *(\mathrm{~B})\end{array}$ & $16,04 * *$ & $1,92^{\text {tn }}$ & $0,61^{\text {tn }}$ & $1,83^{\operatorname{tn}}$ \\
\hline
\end{tabular}

Keterangan (Remarks): ** = Berbeda sangat nyata pada tingkat nyata 5\% (Significantly different at the real level of 5\%), tn = Tidak berbeda nyata pada tingkat nyata $5 \%(\mathrm{tn}=$ Not significantly different at the real level $5 \%$ )

Tabel (Table) 2. Interaksi perlakuan pendahuluan dan metode uji terhadap daya berkecambah benih lamtoro yang ditabur di rumah kaca (Interaction of the preliminary treatment and testing method toeards germination percentage of lamtoro seed sown in the greenhouse)

\begin{tabular}{ccc}
\hline $\begin{array}{c}\text { Perlakuan } \\
\text { Pendahuluan } \\
\text { (Pre-treatments) }\end{array}$ & \multicolumn{2}{c}{ Persen berkecambah (Germination percentage) (\%) } \\
\cline { 2 - 3 } $\mathrm{A}_{1}$ & $\mathrm{C}_{1}$ & $\mathrm{C}_{2}$ \\
$\mathrm{~A}_{2}$ & $20,00 \mathrm{fg}$ & $44,00 \mathrm{~d}$ \\
$\mathrm{~A}_{3}$ & $18,67 \mathrm{~g}$ & $48,67 \mathrm{~cd}$ \\
$\mathrm{~A}_{4}$ & $48,00 \mathrm{~cd}$ & $54,67 \mathrm{c}$ \\
$\mathrm{A}_{5}$ & $\mathbf{9 0 , 0 0} \mathbf{~ a}$ & $81,33 \mathrm{~b}$ \\
$\mathrm{~A}_{6}$ & $\mathbf{8 9 , 3 3 ~ a}$ & $\mathbf{8 8 , 0 0} \mathbf{~ a b}$ \\
$\mathrm{A}_{7}$ & $27,33 \mathrm{ef}$ & $34,00 \mathrm{e}$ \\
& $10,00 \mathrm{~h}$ & $27,33 \mathrm{ef}$
\end{tabular}

Keterangan (Remarks):

$\mathrm{A}_{1}=$ Kontrol (tanpa perlakuan) (Control (without treatment)

$\mathrm{A}_{2}=$ Benih direndam dengan air biasa selama 24 jam (Soaked seeds in plain water for 24 hours)

$\mathrm{A}_{3}=$ Benih direndam dalam air panas (suhu $100^{\circ} \mathrm{C}$ ) dan dibiarkan dingin selama 24 jam (Soaked seeds in boiling water $\left(100^{\circ} \mathrm{C}\right)$ and colded for 24 hours $)$

$\mathrm{A}_{4}=\quad$ Benih direndam dalam $\mathrm{H}_{2} \mathrm{SO}_{4}$ pekat selama 10 menit (Soaked seeds in concentrated $\mathrm{H}_{2} \mathrm{SO}_{4}$ for 10 minutes)

$\mathrm{A}_{5}=$ Benih direndam dalam $\mathrm{H}_{2} \mathrm{SO}_{4}$ pekat selama 20 menit (Soaked seeds in concentrated $\mathrm{H}_{2} \mathrm{SO}_{4}$ for 20 minutes)

$\mathrm{A}_{6}=$ Benih direndam dalam $\mathrm{NaClO} 1 \%$ selama 5 menit (Soaked seeds in 1\% NaClO for 5 minutes)

$\mathrm{A}_{7}=$ Benih direndam dalam NaClO 1\% selama 10 menit (Soaked seeds in 1\% NaClO for 10 minutes)

$\mathrm{C}_{1}=$ Media pasir tanah (1:1) terbuka (The mixture of soil and sand (v/v 1:1) in open area)

$\mathrm{C}_{2}=$ Media pasir tanah (1:1) ditutup plastik selama 1 minggu pertama (The mixture of soil and sand $(\mathrm{v} / \mathrm{v} 1: 1)$ covered with transparent plastic for the first week)

Angka yang diikuti oleh huruf yang sama pada kolom dan baris yang sama tidak berbeda nyata pada tingkat kepercayaan 95\% (Numbers followed by the same letters in the same column and row are not significantly different at the 95\% confidence level) 
Tabel (Table) 3. Kecepatan berkecambah, laju perkecambahan dan nilai perkecambahan pada berbagai perlakuan perkecambahan di rumah kaca (Germination speed, germination rate, mean daily germination and germination value in various germination treatments in the greenhouse)

\begin{tabular}{cccc}
\hline $\begin{array}{l}\text { Perlakuan } \\
\text { pendahuluan } \\
(\text { Pr-etreatments })\end{array}$ & $\begin{array}{c}\text { Kecepatan } \\
\text { perkecambahan } \\
\text { (Germination rate) } \\
\text { (\%/etmal) }\end{array}$ & $\begin{array}{c}\text { Laju perkecambahan } \\
\text { (hari) (Mean daily } \\
\text { germination) (Days) }\end{array}$ & $\begin{array}{c}\text { Nilai } \\
\text { perkecambahan } \\
\text { (Germination } \\
\text { value) }\end{array}$ \\
\hline $\mathrm{A}_{1}$ & $2,49 \mathrm{~d}$ & $16,90 \mathrm{a}$ & $0,80 \mathrm{~d}$ \\
$\mathrm{~A}_{2}$ & $2,48 \mathrm{~d}$ & $16,64 \mathrm{a}$ & $1,06 \mathrm{~d}$ \\
$\mathrm{~A}_{3}$ & $7,93 \mathrm{c}$ & $7,30 \mathrm{~b}$ & $6,62 \mathrm{c}$ \\
$\mathrm{A}_{4}$ & $13,94 \mathrm{~b}$ & $6,82 \mathrm{~b}$ & $24,07 \mathrm{~b}$ \\
$\mathrm{~A}_{5}$ & $\mathbf{1 6 , 2 3} \mathrm{a}$ & $5,75 \mathrm{~b}$ & $\mathbf{3 9 , 6 2} \mathbf{a}$ \\
$\mathrm{A}_{6}$ & $2,55 \mathrm{~d}$ & $15,84 \mathrm{a}$ & $0,86 \mathrm{~d}$ \\
$\mathrm{~A}_{7}$ & $1,67 \mathrm{~d}$ & $14,59 \mathrm{a}$ & $0,33 \mathrm{~d}$ \\
\hline
\end{tabular}

Keterangan (Remarks):

$\mathrm{A}_{1}=$ Kontrol (tanpa perlakuan) (Control (without treatment)

$\mathrm{A}_{2}=\quad$ Benih direndam dengan air biasa selama 24 (Soaked seeds in plain water for 24 hours)

$\mathrm{A}_{3}=$ Benih direndam dalam air panas $\left(\right.$ suhu $100^{\circ} \mathrm{C}$ ) dan dibiarkan dingin selama 24 jam (Soaked seeds in boiling water $\left(100^{\circ} \mathrm{C}\right)$ and colded for 24 hours)

$\mathrm{A}_{4}=\quad$ Benih direndam dalam $\mathrm{H}_{2} \mathrm{SO}_{4}$ pekat selama 10 menit (Soaked seeds in concentrated $\mathrm{H}_{2} \mathrm{SO}_{4}$ for 10 minutes)

$\mathrm{A} 5=\quad$ Benih direndam dalam $\mathrm{H}_{2} \mathrm{SO} 4$ pekat selama 20 menit (Soaked seeds in concentrated $\mathrm{H}_{2} \mathrm{SO}_{4}$ for 20 minutes)

$\mathrm{A}_{6}=$ Benih direndam dalam NaClO $1 \%$ selama 5 menit (Soaked seeds in $1 \% \mathrm{NaClO}$ for 5 minutes)

$\mathrm{A}_{7}=\quad$ Benih direndam dalam $\mathrm{NaClO} 1 \%$ selama 10 menit (Soaked seeds in $1 \% \mathrm{NaClO}$ for 10 minutes)

Angka yang diikuti oleh huruf yang sama pada kolom yang sama tidak berbeda nyata pada tingkat kepercayaan $95 \%$ (Numbers followed by the same letters in the same column are not significantly different at the $95 \%$ confidence level)

Tabel (Table) 4. Kecepatan berkecambah dan laju perkecambahan pada beberapa media perkecambahan di rumah kaca (Germination rate and mean daily germination in some germination media in the greenhouses)

\begin{tabular}{ccc}
\hline $\begin{array}{c}\text { Metode uji } \\
\text { (Testing methods) }\end{array}$ & $\begin{array}{c}\text { Kecepatan berkecambahan } \\
\text { (Germination rate) (\%/etmal) }\end{array}$ & $\begin{array}{c}\text { Laju Perkecambahan (hari) } \\
\text { (Mean Daily Germination) } \\
\text { (days) }\end{array}$ \\
\hline $\mathrm{C} 1$ & $6,05 \mathrm{~b}$ & $13,25 \mathrm{a}$ \\
$\mathrm{C} 2$ & $7,34 \mathrm{a}$ & $11,17 \mathrm{~b}$ \\
\hline
\end{tabular}

Katerangan (Remarks):

$\mathrm{C} 1=$ Media pasir tanah areal terbuka (The mixture of soil and sand in open area) $((\mathrm{v} / \mathrm{v} 1: 1)$

$\mathrm{C} 2=$ Media pasir tanah ditutup plastik selama 1 minggu pertama (The mixture of soil and sand covered with transparent plastic for the first week) (v/v 1: 1)

Angka yang diikuti oleh huruf yang sama pada kolom yang sama tidak berbeda nyata pada tingkat kepercayaan $95 \%$ (Numbers followed by the same letters in the same column are not significantly different at the $95 \%$ confidence level) 
Tabel (Table) 5. Hasil analisis keragaman daya berkecambah dan kecepatan berkecambah benih lamtoro terhadap perlakuan pendahuluan dan kondisi penaburan di laboratorium (Analysis results on germination percentage, germination rate, mean daily germination and germination value of the lamtoro seeds from the pre-treatments and sowing conditions in the laboratory)

\begin{tabular}{|c|c|c|c|c|}
\hline Sumber (Sources) & $\begin{array}{c}\text { Daya perke- } \\
\text { cambahan }(\text { Ger- } \\
\text { mination } \\
\text { capacity) } \\
(\%)\end{array}$ & $\begin{array}{c}\text { Kecepatan } \\
\text { perkecambahan } \\
\text { (Germination } \\
\text { rate }) \\
(\% / \text { etmal }) \\
\end{array}$ & $\begin{array}{c}\text { Laju Perke- } \\
\text { cambahan } \\
\text { (Mean daily } \\
\text { germination) } \\
\text { (Hari/Days) }\end{array}$ & $\begin{array}{c}\text { Nilai perke- } \\
\text { cambahan } \\
\text { (Germination } \\
\text { value })\end{array}$ \\
\hline $\begin{array}{l}\text { Perlakuan pendahuluan } \\
\text { (Pre-treatments) (A) }\end{array}$ & $688,70 * *$ & $1114,99 * *$ & $24,96^{* *}$ & $699,39 * *$ \\
\hline $\begin{array}{l}\text { Metode uji (Test } \\
\text { method) (B) }\end{array}$ & $0,40^{\operatorname{tn}}$ & $0,32^{\operatorname{tn}}$ & $1,46^{\mathrm{tn}}$ & $15,37 * *$ \\
\hline $\begin{array}{l}\text { Interaksi (Interaction) } \\
(\mathrm{A}) *(\mathrm{~B})\end{array}$ & $5,72 * *$ & $6,20 * *$ & $0,50^{\operatorname{tn}}$ & $13,85^{* *}$ \\
\hline
\end{tabular}

Tabel (Table) 6. Daya berkecambah benih lamtoro pada berbagai perlakuan pendahuluan dan metode uji perkecambahan di laboratorium (Germination percentage of lamtoro seeds in various pretreatments and germination test methods in the laboratory)

\begin{tabular}{|c|c|c|c|}
\hline \multirow{3}{*}{$\begin{array}{c}\text { Perlakuan } \\
\text { pendahuluan } \\
\text { (Pre-treatments) }\end{array}$} & \multicolumn{3}{|c|}{ Metode uji (Testing methods) } \\
\hline & $\mathrm{B}_{1}$ & $\mathrm{~B}_{2}$ & $\mathrm{~B}_{3}$ \\
\hline & \multicolumn{3}{|c|}{ Daya berkecambah (Germination percentage) (\%) } \\
\hline $\mathrm{A}_{1}$ & 21,33 ef & 19,33 efgh & 18,00 efgh \\
\hline $\mathrm{A}_{2}$ & $25,33 \mathrm{e}$ & 21,33 efg & $16,67 \mathrm{fgh}$ \\
\hline $\mathrm{A}_{3}$ & $78,00 \mathrm{c}$ & $67,33 \mathrm{~d}$ & $72,67 \mathrm{~cd}$ \\
\hline $\mathrm{A}_{4}$ & $90,67 \mathbf{a b}$ & $87,33 \mathrm{~b}$ & $89,33 \mathbf{a b}$ \\
\hline $\mathrm{A}_{5}$ & $79,33 \mathrm{c}$ & 95,33 a & $87,33 \mathrm{~b}$ \\
\hline $\mathrm{A}_{6}$ & 22,67 ef & $13,33 \mathrm{~h}$ & $22,00 \mathrm{ef}$ \\
\hline $\mathrm{A}_{7}$ & $14,00 \mathrm{gh}$ & $25,33 \mathrm{e}$ & $18,00 \mathrm{efgh}$ \\
\hline
\end{tabular}

\section{Keterangan (Remarks):}

$\mathrm{A}_{1}=$ Kontrol (Control)

$\mathrm{A}_{2}=$ Benih direndam dengan air biasa selama 24 jam (Soaked seeds in plain water for 24 hours)

$\mathrm{A}_{3}=$ Benih direndam dalam air panas (suhu $100^{\circ} \mathrm{C}$ ) dan dibiarkan dingin selama 24 jam (Soaked seeds in boiling water $\left(100^{\circ} \mathrm{C}\right)$ and colded for 24 hours)

$\mathrm{A}_{4}=$ Benih direndam dalam $\mathrm{H}_{2} \mathrm{SO}_{4}$ pekat selama 10 menit (Soaked seeds in concentrated $\mathrm{H}_{2} \mathrm{SO}_{4}$ for 10 minutes)

$\mathrm{A}_{5}=$ Benih direndam dalam $\mathrm{H}_{2} \mathrm{SO}_{4}$ pekat selama 20 menit (Soaked seeds in concentrated $\mathrm{H}_{2} \mathrm{SO}_{4}$ for 20 minutes)

$\mathrm{A}_{6}=$ Benih direndam dalam $\mathrm{NaClO} 1 \%$ selama 5 menit (Soaked seeds in 1\% NaClO for 5 minutes)

$\mathrm{A}_{7}=$ Benih direndam dalam $\mathrm{NaClO} 1 \%$ selama 10 menit (Soaked seeds in 1\% NaClO for 10 minutes)

$\mathrm{B}_{1}=\mathrm{UDK}$ (Uji Di atas Kertas) (Top of Paper)

$\mathrm{B}_{2}=\mathrm{UAK}$ (Uji Antar Kertas) (Inter of Paper)

$\mathrm{B}_{3}=\operatorname{UKDdp}$ (Uji Kertas Digulung didirikan dalam plastik) (Rolled Paper Tests are erected in plastic)

Angka yang diikuti oleh huruf yang sama pada kolom yang sama tidak berbeda nyata pada tingkat kepercayaan $95 \%$ (Numbers followed by the same letters in the same column are not significantly different at the $95 \%$ confidence level). 
Tabel (Table) 7. Kecepatan berkecambah benih lamtoro pada berbagai perlakuan pendahuluan dan metode uji perkecambahan di laboratorium (Germination rate of lamtoro seeds in various pre-treatments and germination test methods in the laboratory)

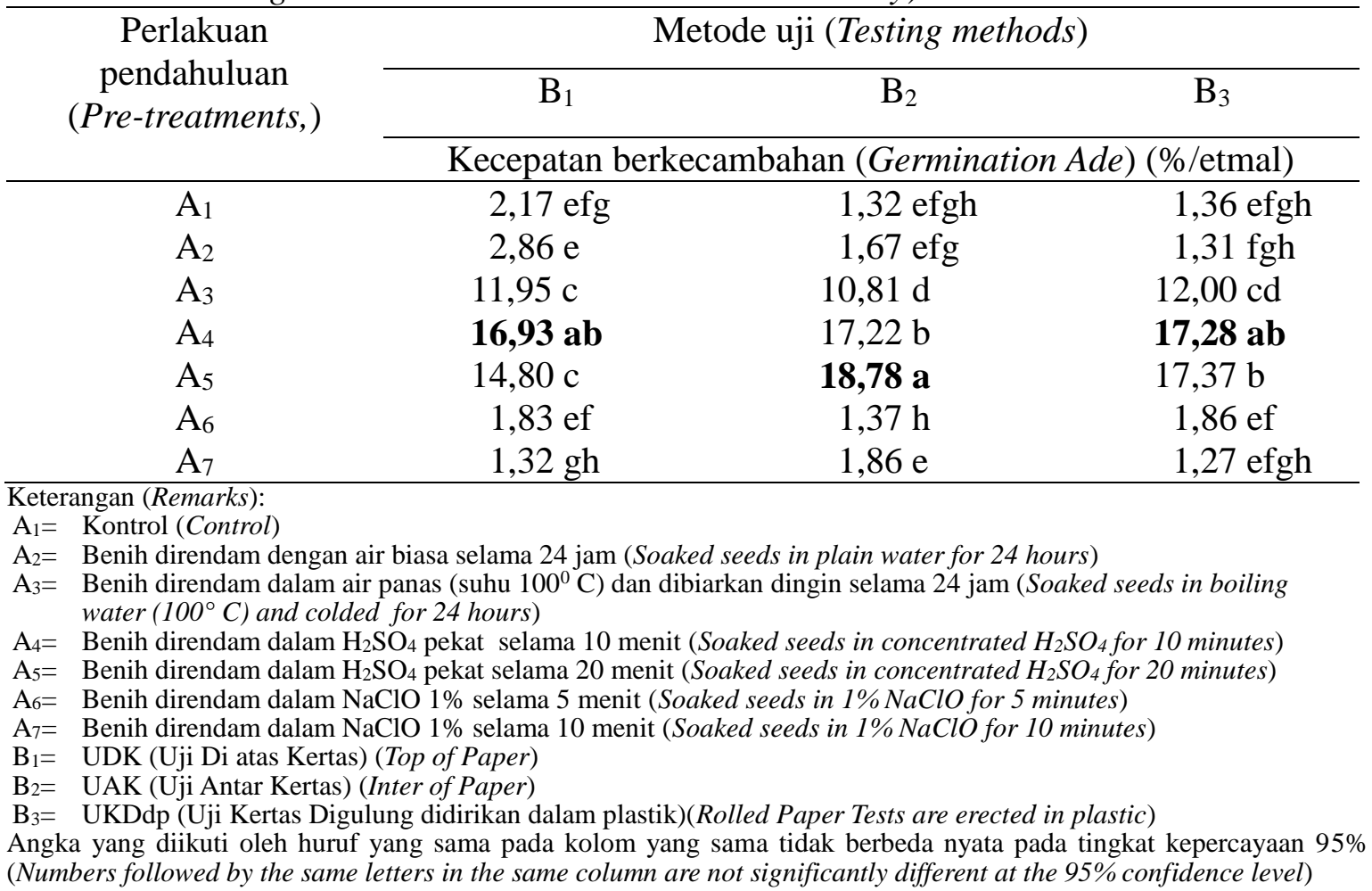

Tabel (Table) 8. Nilai perkecambahan benih lamtoro pada berbagai perlakuan pendahuluan dan metode uji perkecambahan di laboratorium (Germination value of lamtoro seeds in various pre-treatments and germination test methods in the laboratory)

\begin{tabular}{|c|c|c|c|}
\hline \multirow{3}{*}{$\begin{array}{c}\text { Perlakuan } \\
\text { pendahuluan } \\
\text { (Pre-treatments, })\end{array}$} & \multicolumn{3}{|c|}{ Metode uji/Testing methods } \\
\hline & $\mathrm{B}_{1}$ & $\mathrm{~B}_{2}$ & $\mathrm{~B}_{3}$ \\
\hline & \multicolumn{3}{|c|}{ Nilai perkecambahan/Germination Value } \\
\hline $\mathrm{A}_{1}$ & $0,39 \mathrm{~g}$ & $0,11 \mathrm{~g}$ & $0,24 \mathrm{~g}$ \\
\hline $\mathrm{A}_{2}$ & $1,41 \mathrm{~g}$ & $0,44 \mathrm{~g}$ & $0,10 \mathrm{~g}$ \\
\hline $\mathrm{A}_{3}$ & $22,35 \mathrm{e}$ & $17,97 \mathrm{f}$ & $22,35 \mathrm{e}$ \\
\hline $\mathrm{A}_{4}$ & $42,67 \mathrm{c}$ & $48,91 \mathrm{~b}$ & $50,44 \mathrm{~b}$ \\
\hline $\mathrm{A}_{5}$ & $32,10 \mathrm{~d}$ & 58,48 a & $50,52 \mathrm{~b}$ \\
\hline $\mathrm{A}_{6}$ & $0,33 \mathrm{~g}$ & $0,42 \mathrm{~g}$ & $0,24 \mathrm{~g}$ \\
\hline $\mathrm{A}_{7}$ & $0,31 \mathrm{~g}$ & $0,53 \mathrm{~g}$ & $0,14 \mathrm{~g}$ \\
\hline
\end{tabular}

Keterangan (Remarks):

$\mathrm{A}_{1}=$ Kontrol (Control)

$\mathrm{A}_{2}=$ Benih direndam dengan air biasa selama 24 jam (Soaked seeds in plain water for 24 hours)

$\mathrm{A}_{3}=$ Benih direndam dalam air panas $\left(\right.$ suhu $\left.100^{\circ} \mathrm{C}\right)$ dan dibiarkan dingin selama 24 jam (Soaked seeds in boiling water $\left(100^{\circ} \mathrm{C}\right)$ and colded for 24 hours $)$

$\mathrm{A}_{4}=$ Benih direndam dalam $\mathrm{H}_{2} \mathrm{SO}_{4}$ pekat selama 10 menit (Soaked seeds in concentrated $\mathrm{H}_{2} \mathrm{SO}_{4}$ for 10 minutes)

$\mathrm{A}_{5}=$ Benih direndam dalam $\mathrm{H}_{2} \mathrm{SO}_{4}$ pekat selama 20 menit (Seeds soaked in concentrated $\mathrm{H}_{2} \mathrm{SO}_{4}$ for 20 minutes)

$\mathrm{A}_{6}=$ Benih direndam dalam NaClO $1 \%$ selama 5 menit (Soaked seeds in 1\% NaClO for 5 minutes)

$\mathrm{A}_{7}=$ Benih direndam dalam NaClO $1 \%$ selama 10 menit (Soaked seeds in $1 \%$ NaClO for 10 minutes)

$\mathrm{B}_{1}=\mathrm{UDK}$ (Uji Di atas Kertas) (Top of Paper)

$\mathrm{B}_{2}=\mathrm{UAK}$ (Uji Antar Kertas) (Inter of Paper)

$\mathrm{B}_{3}=$ UKDdp (Uji Kertas Digulung didirikan dalam plastik) (Rolled Paper Tests are erected in plastic)

Angka yang diikuti oleh huruf yang sama pada kolom yang sama tidak berbeda nyata pada tingkat kepercayaan $95 \%$ (Numbers followed by the same letters in the same column are not significantly different at the 95\% confidence level) 
Tabel (Table) 9. Laju perkecambahan benih lamtoro pada berbagai perlakuan pendahuluan di laboratorium (Mean Daily Germination of Lamtoro seed in various pretreatments in the laboratory)

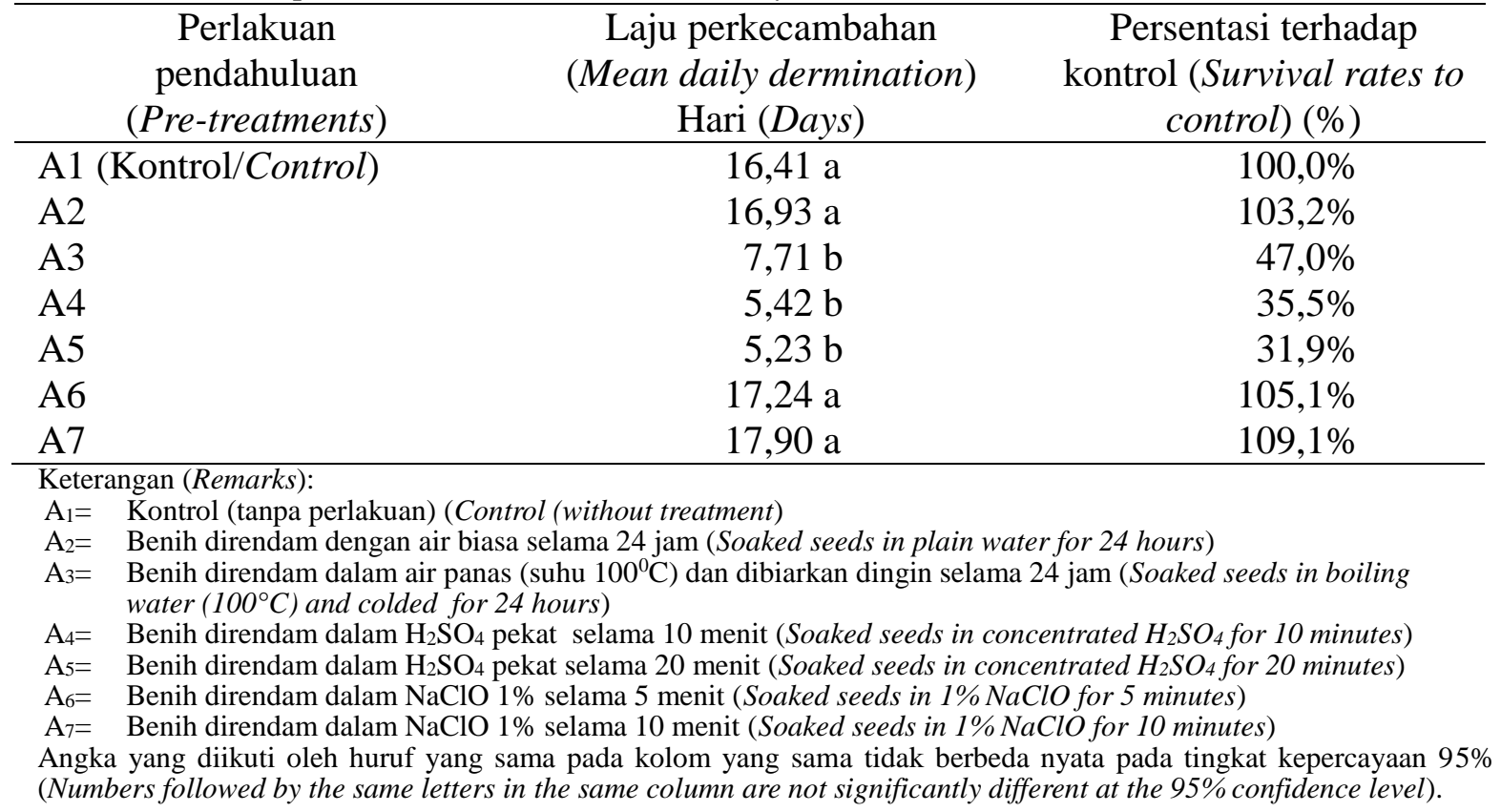

\section{B. Pembahasan}

Benih lamtoro mempunyai kulit benih yang keras, kulit benih yang keras mempunyai sifat dormansi yaitu suatu kondisi dimana benih hidup tidak berkecambah sampai batas waktu akhir pengamatan perkecambahan (akhir pengamatan sesuai standar pengujian dan mutu benih tanaman hutan (Sudrajat, Nurhasybi, \& Bramasto, 2015), walaupun faktor lingkungan optimum untuk perkecambahannya, sehingga untuk perkecambahannya diperlukan perlakuan pendahuluan terlebih dahulu (Murniati, 2013), dan untuk mendapatkan metode perkecambahan yang tepat diperlukan metode uji yang cocok untuk benih lamtoro. Hasil interaksi antara faktor perlakuan pendahuluan dan faktor metode uji di rumah kaca yang dapat meningkatkan daya berkecambah benih lamtoro yang ditabur dengan bak kecambah terbuka yang telah menghasilkan daya berkecambah yang tertinggi yaitu benih yang diberi perlakuan benih direndam dengan $\mathrm{H}_{2} \mathrm{SO}_{4}$ selama 10 menit sebesar 90\% (Tabel 2), namun tidak berbeda nyata dengan perlakuan perendaman $\mathrm{H}_{2} \mathrm{SO}_{4}$ selama 20 menit dengan ditabur pada bak kecambah terbuka dan tertutup dengan menghasilkan daya berkecambah $89 \%$ dan $88 \%$. Ini menunjukkan bahwa perendaman dengan $\mathrm{H}_{2} \mathrm{SO}_{4}$ selama 10 menit dan 20 menit dapat mematahkan dormansi benih lamtoro dengan baik dan meningkatkan viabilitas benih lamtoro, sedangkan metode penaburan tidak berpengaruh terhadap daya berkecambah benih lamtoro.

Kecepatan tumbuh benih adalah tolok ukur vigor kekuatan tumbuh benih, dimana benih yang cepat tumbuh akan lebih mampu mengatasi kondisi lapang yang sub optimum dan dapat bersaing dengan gulma (Widajati, 2013). Perlakuan pendahuluan yang dapat menghasilkan kecepatan perkecambahan tertinggi adalah perlakuan pendahuluan benih direndam $\mathrm{H}_{2} \mathrm{SO}_{4}$ selama 20 menit dengan kecepatan berkecambah 16,23\%/etmal. Perendaman dengan $\mathrm{H}_{2} \mathrm{SO}_{4}$ selama 20 menit ini juga dapat mempercepat laju perkecambahan dari 16,9 hari (kontrol) menjadi 5,8 hari 
dan meningkatkan nilai perkecambahan dari 0,8 (kontrol) menjadi 39,6. Selain perlakuan pendahuluan dengan $\mathrm{H}_{2} \mathrm{SO}_{4}$, ternyata metode uji juga dapat mempengaruhi kecepatan perkecambahan dan laju perkecambah. Metode uji yang dapat meningkatkan kecepatan dan laju perkecambahan adalah media pasir tanah yang ditutup plastik. Dengan demikian, benih lamtoro yang dikecambahkan di rumah kaca dengan media pasir tanah yang ditutup plastik, menghasilkan kecambah yang lebih vigor.

Interaksi faktor perlakuan pendahuluan dan faktor metode uji benih lamtoro yang dikecambahkan di laboratorium menunjukkan bahwa hasil daya berkecambah, kecepatan berkecambah dan nilai perkecambahan tertinggi terdapat pada benih yang diberi perlakuan pendahuluan direndam $\mathrm{H}_{2} \mathrm{SO}_{4}$ selama 20 menit dengan metode Uji Antar Kertas (UAK) dengan daya berkecambah sebesar 95\%, kecepatan berkecambah 18,78\%/etmal dan nilai perkecambahan 58,5. Hasil pengujian perkecambahan di laboratorium ini menunjukkan bahwa yang terbaik untuk meningkatkan daya berkecmbah, kecepatan berkecambah dan nilai perkecambahan adalah benih diberi perlakuan direndam $\mathrm{H}_{2} \mathrm{SO}_{4}$ selama 20 menit dan ditabur dengan metode Uji Antar Kertas (UAK). Dengan demikian, benih lamtoro yang dikecambahkan di rumah kaca maupun di laboratorium dengan memberikan perlakuan pendahuluan perendaman $\mathrm{H}_{2} \mathrm{SO}_{4}$, telah menghasilkan perkecambahan terbaik. Perendaman dengan $\mathrm{H}_{2} \mathrm{SO}_{4}$ merupakan skarifikasi asam yang sangat efektif untuk beberapa jenis tanaman yang mempunyai kulit benih keras. Diketahui bahwa $\mathrm{H}_{2} \mathrm{SO}_{4}$ berfungsi untuk melunakkan kulit benih sehingga dapat dilalui air dengan mudah. Beberapa hasil penelitian yang menggunakan $\mathrm{H}_{2} \mathrm{SO}_{4}$ untuk meningkatkan perkecambahan benih seperti jenis mindi yang direndam dengan $\mathrm{H}_{2} \mathrm{SO}_{4}$ selama 30 dan 20 menit menghasilkan perkecambahan $74 \%$ dan 80\% (Azad, Al-Musa, \& Matin, 2010).
Jenis mucuna yang mempunyai dormansi kulit biji yang dilakukan dengan menggunakan $\mathrm{H}_{2} \mathrm{SO}_{4}$ selama 10 menit menghasilkan daya berkecambah yang tinggi yaitu 92\% (Astari, Rosmayati, \& Bayu, 2014). Untuk jenis pilang yang direndam dengan $\mathrm{H}_{2} \mathrm{SO}_{4}$ pekat selama 20 menit menghasilkan daya berkecambah $56 \%$ dan yang tanpa perlakuan $0 \%$ (Suita \& Bustomi, 2014), serta untuk jenis Acacia erioloba yang direndam $\mathrm{H}_{2} \mathrm{SO}_{4}$ selama 6 menit dapat menghasilkan daya berkecambah 88\% (Rasebeka et al., 2014), begitu juga jenis weru dengan menggunakan perlakuan perendaman $\mathrm{H}_{2} \mathrm{SO}_{4}$ selama 10 menit dapat menghasilkan daya berkecambah mencapai 93\% (Suita \& Nurhasybi, 2014). Benih Acacia crassicarpa yang direndam dengan $\mathrm{H}_{2} \mathrm{SO}_{4}$ pekat menghasilkan daya berkecambah $96 \%$ selama 30 menit.

Menurut Suita \& Syamsuwida (2017) bahwa metode Uji Di atas Kertas (UDK) merupakan metode yang baik digunakan untuk benih yang membutuhkan cahaya bagi perkecambahannya, sedangkan metode Uji Antar Kertad (UAK) dan Uji Kertas Digulung didirikan dalam plastic (UKDdp) digunakan bagi benih yang tidak peka terhadap cahaya untuk perkecambahannya. Jadi untuk benih lamtoro (Tabel 6) dapat menghasilkan daya berkecambah, dan kecepatan berkecambah yang baik dengan adanya cahaya maupun tanpa cahaya, tetapi untuk mendapatkan nilai perkecambahan yang tinggi, maka sebaiknya dikecambahkan di laboratorium dengan metode Uji Antar Kertas (UAK), karena untuk mencapai nilai perkecambahan tertinggi tidak diperlukan cahaya.

Perlakuan perendaman dengan air panas juga merupakan perlakuan yang dapat meningkatkan daya berkecambah benih yang mempunyai dormansi kulit benih karena fungsi air panas dapat melunakkan kulit benih, untuk benih lamtoro yang ditabur pada bak kecambah tertutup sudah mampu menghasilkan daya berkecambah rata-rata $55 \%$, dan kontrol 
hanya 44\% (Tabel 3). Benih yang ditabur di laboratorium dengan metode UDK menghasilkan daya berkecambah $78 \%$ dan kontrol hanya 21,33\% (Tabel 6). Dengan demikian, untuk melakukan pengujian benih lamtoro yang menggunakan perlakuan perendaman air panas sebaiknya diuji dengan metode UDK di laboratorium agar menghasilkan hasil yang optimal. Perlakuan perendaman dengan suhu air panas $70^{\circ} \mathrm{C}$ dapat menghasilkan persentase perkecambahan $75 \%$ dan direndam dalam air $70^{\circ} \mathrm{C}$ selama 20 menit dapat menghasilkan daya berkecambah $68 \%$ (Tadros et al., 2011), sedangkan perendaman dalam air panas selama 6 menit menghasilkan daya berkecambah 58\% (Fitri, 2015). Penelitian perendaman dengan air panas untuk jenis lainnya yang dapat meningkatkan perkecambahan diantaranya benih sengon (Marthen et al., 2013), yang dicelupkan ke dalam air panas $60^{\circ} \mathrm{C}$ selama 2-6 menit kemudian direndam air dingin selama 12 jam menghasilkan daya berkecambah $100 \%$, dan jenis papaya menurut (Aisyah \& Herrianto, 2016) dengan suhu air perendaman $60^{\circ} \mathrm{C}$ dapat mematahkan dormansi benihnya.

Perlakuan perendaman dengan $\mathrm{NaOCl}$ yang ditabur pada bak kecambah terbuka belum dapat meningkatkan daya berkecambah dan kecepatan berkecambah benih lamtoro ( $10 \%$ dan $0,71 \% \mathrm{KN} / \mathrm{etmal})$ dan cendrung lebih rendah dari kontrol (20\% dan 1,56\% KN/etmal). Benih segar dan sehat jika diberi perlakuan $\mathrm{NaOCl}$ maka daya berkecambah akan menurun (Suharti \& Suita, 2013). Hal ini karena senyawa kimia dapat merusak kulit benih yang sehat dan dapat meracuni benih yang pada akhirnya dapat berakibat benih mati. Peningkatan daya berkecambah dan kecepatan berkecambah akan terjadi apabila ditabur pada bak kecambah ditutup plastik ( $27 \%$ dan $2,63 \% \mathrm{KN} / \mathrm{etmal})$, ini menunjukkan bahwa perkecambahan benih memerlukan suhu dan kelembaban yang cukup tinggi karena bak kecambah yang ditutup plastik, maka suhu dan kelembabannya akan meningkat. Menurut (Suita \& Syamsuwida, 2017), penutupan persemaian dengan lembaran plastik selama perkecambahan, menyebabkan peningkatan suhu di persemaian. Oleh karena itu, kondisi ini diduga menjadi stimulan untuk proses perkecambahan benih untuk mencapai kapasitas perkecambahan yang lebih tinggi.

\section{KESIMPULAN DAN SARAN}

\section{A. Kesimpulan}

Pengujian viabilitas benih lamtoro baik penaburan di rumah kaca maupun di laboratorium yang dapat menigkatkan daya berkecambah, kecepatan berkecambah, laju perkecambahan dan nilai perkecambahan yang diberikan perlakuan benih direndam $\mathrm{H}_{2} \mathrm{SO}_{4}$ selama 20 menit. Untuk metode uji penaburan di rumah kaca pada media pasir tanah ditutup pasir dan di laboratorium dengan metode Uji Di atas Kertas (UDK).

\section{B. Saran}

Perlakuan pendahuluan benih lamtoro dengan cara benih direndam $\mathrm{H}_{2} \mathrm{SO}_{4}$ selama 20 menit dapat meningkatkan viabilitas dan vigor benih, sehingga perlakuan tersebut diharapkan dapat digunakan dalam perkecambahan benih untuk menunjang program penanaman.

\section{UCAPAN TERIMA KASIH}

Ucapan terima kasih disampaikan kepada Saudara Suherman dan Ateng Rahmat Hidayat atas bantuannya dalam pengamatan dan pengumpulan data selama kegiatan penelitian

\section{DAFTAR PUSTAKA}

Adawiah, R.A.R. (2018). Potensi ekstrak daun lamtoro (leucaena leucocephala lam.) sebagai bioherbisida terhadap pertumbuhan beberapa jenis gulma. Universitas Islam Negeri Maulana 
Malik Ibrahim, Malang. Retrieved from http://e-journal.uajy.ac.id/ 14649/1/JURNAL.

Aisyah, S., \& Herrianto, E. (2016). Pelepasan kulit ari dan suhu perendaman terhadap pematahan dormansi benih pepaya. Jurnal Biologi Dan Pembelajaran Biologi, 1(1), 81-93.

Roidi, A.A. (2016). Pengaruh pemberian pupuk cair daun lamtoro terhadap pertumbuhan dan produktivitas tanaman sawi pakcoy. Universitas Sanata Dharma. Retrieved from https://repository.usd.ac.id/8151/2/121 434023_full.

Astari, R.P., Rosmayati, \& Bayu, E.S. (2014). Pengaruh pematahan dormansi secara fisik dan kimia terhadap kemampuan berkecambah benih mucuna (Mucuna bracteata D.C). Jurnal Online Agroekoteknologi, 2(2), 803-812.

Azad, S., Al-Musa, Z., \& Matin, A. (2010). Effects of pre-sowing treatments on seed germination of Melia azedarach. Journal of Forestry Research, 21(2), 193-196.

https://doi.org/10.1007/s11676-0100031-1

Fitri, N. (2015). Pengaruh skarifikasi dengan perendaman dalam aquades, air panas, dan asam sulfat terhadap perkecambahan biji dan pertumbuhan awal lamtoro (Leucaena leucocephala). Universitas Hasanuddin Makassar.

Marthen, Kaya, \& Rehatta. (2013). Pengaruh perlakuan pencelupan dan perendaman terhadap perkecambahan benih sengon. Agrologia, 2(1), 10-16.

Murniati, E. (2013). Fisiologi perkecambahan dan dormansi benih. In Dasar Ilmu dan Teknologi Benih. IPB Press.

Olatunji, D., Maku, J.O., \& Odumefun, O.P. (2013). The effect of pretreatments on the germination and early seedlings growth of Acacia auriculiformis Cunn . Ex . Benth. African Journal of Plant Science, 7(8), 325-330. https://doi.org/10.5897/AJPS11.255

Orwa, C., Mutua, A., Kindt, R., \& Anthony, S. (2009). Leucaena leucocephala (Lam) de Wit Fabaceae - Mimosoideae.

Rasebeka, L., Mathowa, T., \& Mojeremane, W. (2014). Effect of seed pre-sowing treatment on germination of three Acacia species Indigenous to Botswana. International Journal of Plant \& Soil Science, 3(1), 62-70.

Sudrajat, D.J., Nurhasybi, \& Bramasto, Y. (2015). Standar Pengujian dan Mutu Benih Tanaman Hutan. (Iriantono, D., Zanzibar, M., \& Setio, P. Eds.). Forda Press, Bogor.

Suharti, T., \& Suita, E. (2013). Pengaruh fungisida terhadap viabilitas benih lamtoro (Leucaena leucocephala). Jurnal Perbenihan Hutan Tanaman, 1(2), 103-109.

Suita, E., \& Bustomi, S. (2014). Teknik peningkatan daya dan kecepatan berkecambah benih pilang. Jurnal Penelitian Hutan Tanaman, 11(1), 4552.

Suita, E., \& Nurhasybi. (2014). Pengujian viabilitas benih weru (Albizia procera Benth.). Jurnal Perbenihan Tanaman Hutan, 2(1), 12-23.

Suita, E., \& Syamsuwida, D. (2017). 
Karakteristik fisik dan metode pengujian perkecambahan benih turi (Sesbania grandiflora (L.) Pers.). Jurnal Perbenihan Tanaman Hutan, 5(2), 125-135.

Sutopo, L. (2002). Teknologi benih (Cetakan ke). Jakarta: Raja Grafindo Persada.

https://doi.org/10.1163/157006610X5 30330

Tadros, M.J., Samarah, N.H., \& Alqudah, A.M. (2011). Effect of different pre- sowing seed treatments on the germination of Leucaena leucocephala (Lam.) and Acacia farnesiana (L.). New Forests, 42(3), 397-407.

https://doi.org/10.1007/s11056-0119260-1

Widajati, E. (2013). Batasan benih, aspekaspek dalam ilmu dan teknlogi benih, serta pentingnya benih dalam produksi tanaman. In Dasar Ilmu dan Teknologi Benih. IPB Press, Bogor. 